ARTÍCULO DE REVISIÓN

\title{
Virtopsia. Su pertinencia como herramienta de apoyo judicial en Colombia
}

Virtopsy. Its relevance as s judicial support tool in Colombia

\author{
Angélica N. García-Robelto ${ }^{1}$ \\ Alejandro Betín-Isaza² \\ Aura M. Gil-Villa ${ }^{3}$
}

Tipo de artículo: Artículo de revisión. Recibido: 03 de octubre de 2019. Aprobado: 05 de diciembre de 2019.

Resumen: La autopsia convencional es un procedimiento que se realiza para determinar las causas de muerte de un individuo, utilizando equipamiento quirúrgico elemental. La autopsia virtual o la virtopsia, consiste en la realización de autopsias con equipos y métodos de alta tecnología como resonancia magnética, tomografía axial computarizada y radiología, donde el médico puede visualizar los hallazgos en imágenes digitalizadas y/o realizar una reconstrucción exhaustiva de lo ocurrido en el cuerpo de la víctima. En el presente artículo, se obtuvo información sobre la virtopsia y su pertinencia como herramienta de apoyo judicial en Colombia, para lo cual se consultaron artículos científicos publicados en revistas nacionales e internacionales, manuales del Instituto Nacional de Medicina Legal y la legislación colombiana, publicados entre los años 1990 y 2019 . Se utilizaron bases de datos y buscadores como Google Académico, ScienceDirect, Scopus, Springer y Ebsco Host, y los descriptores: autopsia, médico forense, ciencias forenses, radiología y tomografía computarizada. Colombia podría implementar la virtopsia como técnica complementaria a la autopsia convencional, mediante la integración de servicios ofrecidos por entidades estatales como el Instituto Nacional de Medicina Legal y por universidades públicas y privadas que, hasta la actualidad, se han encargado de la formación de investigadores en el área de criminalística y ciencias forenses.

Palabras claves: autopsia, virtopsia, ciencias forenses, radiología y tomografía computarizada.

Abstract: Conventional autopsy is a procedure that is performed to determine the causes of a person's death, by means of simple surgical instruments. Virtual autopsy or virtopsy, is performed with high-tech equipment and methods such as magnetic resonance imaging, computed tomography and radiology. The pathologist can visualize the findings in scanned images and

1 Técnico profesional en Criminalística. Corporación de Educación Superior ISES. Estudiante de Profesional en Criminalística de la Facultad de Derecho y Ciencias Forenses, Tecnológico de Antioquia - Institución Universitaria, Medellín, Colombia. Calle 78B N 72A- 220, MedellínColombia. Código Postal 050036. Correo electrónico: angelicanaydu@hotmail.com.

2 Estudiante de Profesional en Criminalística de la Facultad de Derecho y Ciencias Forenses, Tecnológico de Antioquia - Institución Universitaria, Medellín, Colombia.

3 Doctora en Ciencias Básicas Biomédicas. Docente investigadora. Grupo de Investigación BISMA. Facultad de Derecho y Ciencias Forenses, Tecnológico de Antioquia - Institución Universitaria, Medellín-Colombia. CvLac: https://scienti.colciencias.gov.co/cvlac/visualizador/ generarCurriculoCv.do?cod_rh=0000532002 
perform a reconstruction of the event that caused the death of the victim. This article provides information related to the relevance of virtopsy as a judicial support tool in Colombia. Documents published between 1990 and 2019 in scientific articles from national and international journals, manuals of the National Institute of Legal medicine and Colombian legislation were consulted. Databases and search engines as for instance Google Scholar, Science Direct, Scopus, Springer and Ebsco Host, and descriptors such as autopsy, coroner, forensic sciences, radiology and computed tomography were used. Colombia could implement virtopsy as a complementary technique to the conventional autopsy, through integration of services offered by state entities such as the National Institute of Legal Medicine and public and private universities responsible for training investigators in the area of criminalistics and forensic sciences.

Keywords: autopsy, virtopsy, forensic sciences, radiology and computed tomography.

Cómo citar este artículo: García Robelto, A. N., Betín Isaza, A., y Gil-Villa, A. M. (2020). Virtopsia. Su pertinencia como herramienta de apoyo judicial en Colombia. Memorias Forenses, (3), 45-58.

\section{Introducción}

La autopsia (del griego autopsia, o acción de ver con los propios ojos) se define como un examen anatómico de un cadáver mediante el cual se pueden analizar de forma minuciosa órganos y estructuras internas después de una disección para determinar la causa de muerte o el carácter de cambios patológicos (Teijeira, Bañón, Hidalgo y Pradini, 2006). Por su parte, la autopsia médico-legal es el conjunto de actos técnico-científicos realizados por un médico forense que está capacitado para realizar exámenes anatomopatológicos con el fin de determinar lesiones o causas de muerte de un individuo a consecuencia de hechos violentos o sospechosos de criminalidad (Teijeira et al., 2006).

Las ciencias forenses en algunos países han evolucionado mediante la implementación tecnológica de métodos avanzados para la realización de autopsias: uno de ellos es la autopsia virtual, un procedimiento no invasivo en el cual se muestran imágenes en tres dimensiones mediante un escaneo general del cuerpo por medio de tomografías computarizadas, radiologías, resonancias magnéticas entre otros elementos tecnológicos (Dirnhofer, Thali, Jackowski, Potter y Vock, 2006). También se han ido incorporando nuevas técnicas que permiten la utilización de imágenes de alta resolución, las cuales generan un conjunto de datos almacenados (ficheros) que permiten la reconstrucción 3D, 4D y 5D del cuerpo en examen, y permiten la ejecución de diferentes tipos de análisis y procesamiento de imágenes y observación corporal de un individuo de una manera indirecta pero precisa e interactiva (Castro, Roque, Garcés y Oliver, 2017). Esta innovación tecnológica se presenta como un instrumento de importante utilidad para el área forense, debido a la capacidad de realizar un escaneo de toda la superficie del cuerpo, para propiciar la pronta detección de la causa de muerte y agilizar el proceso legal referente al caso de estudio (Castro et al., 2017).

La implementación de la autopsia virtual comenzó en el año 2000 en el Instituto de Medicina Legal Forense de la Universidad de Berna, Suiza, con la intención de propiciar nuevas técnicas radiológicas en beneficio de las ciencias forenses (EstudioGalton, 2010). Actualmente, el Instituto de Medicina Forense de Zurich lleva varios años utilizando esta tecnología e incluso incorporando sistemas denominados virtobot, un robot que permite la automatización del proceso, la documentación de superficies en 3D con alta resolución, así como la tomografía computarizada post mórtem guiada (Breitbeck et al., 2014). Por su parte, en Colombia se realiza la necropsia médico-legal en la cual se manejan los principios y conocimientos de las ciencias médicas en la aplicación de técnicas y procedimientos para 
determinar la causa y la manera de muerte, seguida de métodos y protocolos estables para la realización de la autopsia (Gisbert, 2004).

La autopsia no sólo consiste en describir hallazgos como cambios anatómicos o patológicos, sino también transmitir los resultados mediante un fundamento científico de un trabajo en equipo, que contribuya a esclarecer las posibles causas de las muertes súbitas o de los homicidios; es poder entregar herramientas que soporten las responsabilidades legales a partir de los aportes y experticias de un profesional (Gisbert, 2004). De esta manera, el objetivo de la presente revisión corta de la literatura es buscar información acerca de la pertinencia de la autopsia virtual como herramienta de apoyo para ser aplicada en Colombia.

\section{Metodología}

La presente revisión está basada en artículos científicos, revistas de salud, manuales del Instituto Nacional de Medicina Legal y en la legislación colombiana; documentos publicados entre los años 1990 y 2019, localizados mediante la búsqueda en bases de datos como Google Académico, ScienceDirect, Scopus, Springer y Ebsco Host. Se emplearon los siguientes descriptores de búsqueda: autopsia, médico forense, ciencias forenses, radiología y tomografía computarizada para el correcto desarrollo del artículo. La información fue clasificada sobre definiciones y antecedentes de la autopsia, su importancia en el campo investigativo con respecto a la legislación colombiana y los avances tecnológicos que han ocurrido (ver Tabla 1).

\section{La autopsia convencional y sus generalidades}

La autopsia es un procedimiento que permite a través de la observación, la intervención y el análisis interno y externo de un cadáver, obtener información para fines científicos y/o jurídicos con el apoyo de evidencias físicas o elementos materiales probatorios relacionados con el cuerpo. Este procedimiento se realiza por medio de la viscerotomía, que es la recolección de órganos y toma de muestras de cualquier componente anatómico contenido en las cavidades del cuerpo humano (Minsalud, Decreto 786 de 1990).
El marco legal vigente para la práctica de necropsias en Colombia está contenido en el Decreto 786 de 1990 (Minsalud, 1990) donde se destacan diez componentes básicos que deben tenerse en cuenta en el momento de realizar la práctica de una necropsia médico-legal:

1. Información disponible: Antes de abordar la necropsia, el médico forense debe conocer toda la información y acceder a documentos técnicos de utilidad como fotos, croquis, diagramas y planos de la escena, declaraciones de testigos, historias clínicas, etc.

2. Cadena de custodia: Permite el seguimiento, información y control de elementos materiales probatorios con el fin de garantizar su integridad, identidad, preservación, seguridad y aptitud a lo largo del proceso investigativo.

3. Manejo de evidencia física del cadáver.

4. Identificación: La autoridad que realiza la diligencia de inspección al cadáver, usualmente suministra al perito la información necesaria sobre la identidad del fallecido y registra en la solicitud de necropsia opiniones sobre la necesidad de establecer la identidad técnicamente o verificarla.

5. Examen externo.

6. Técnicas de exploración del cadáver.

7. Examen interno.

8. Opinión pericial: Aquí se describe la causa y la manera de muerte.

9. Protocolo de necropsia: Es un documento médico donde se registran todos los hallazgos del examen realizado al cadáver.

10.Oportunidad: Se refiere a que la información obtenida de la necropsia debe estar disponible de manera oportuna para los fines de la investigación judicial y cuando la autoridad competente así lo requiera (INMLYCF, 2004).

Las necropsias se pueden realizar en casos de muertes debidas a lesiones por proyectil de arma de fuego, arma blanca, compresión del cuello, trauma contundente, muertes asociadas con quemaduras, drogas ilícitas, etc.; en cada uno de los casos se debe realizar toma de muestra de diferentes órganos para ser analizados o preservados según el laboratorio correspondiente (INMLYCF, 2004). Por su parte, la preservación de elementos materiales 
probatorios y el adecuado registro documental son procedimientos básicos para el éxito de una necropsia; el segundo aspecto se refiere al registro detallado y sistemático de los hallazgos y de las actividades realizadas, por escrito, por fotografía y/o por otros medios audiovisuales. La preservación se refiere a la obtención, conservación y manejo de las evidencias físicas, cumpliendo criterios de legalidad, cadena de custodia y calidad técnica (INMLYCF, 2004).

\section{Autopsia virtual: el nuevo avance para la medicina forense}

Los datos obtenidos de una autopsia convencional se recopilan y los expertos forenses se encargan de su análisis y emisión de conclusiones. Luego, el cadáver es entregado a sus familiares para llevar a cabo las ceremonias religiosas o culturales asociadas al proceso de muerte. Sin embargo, si el experto forense requiere considerar o confirmar su decisión sobre los datos recopilados, el acceso al cadáver podría llegar a ser difícil e incluso inviable (Dirnhofer et al., 2006). La posible mutilación involucrada en la autopsia convencional a menudo deja a las familias afligidas o perturbadas, con lo cual declaran un concepto desfavorable para Llevar a cabo el procedimiento. Además, ciertos grupos religiosos, como judíos, musulmanes y testigos de Jehová, no aceptan completamente los procedimientos asociados a la práctica de la autopsia convencional (Pomara, Fineschi, Scalzo y Guglielmi, 2009).

A finales de la década de 1990, un caso de homicidio de alto perfil en Suiza exigía una opinión forense precisa; las impresiones del cráneo de la víctima tuvieron que ser cotejadas con un elemento material probatorio de importante relevancia. El extenso trabajo realizado en este campo se centró en un método de análisis forense que perturbara mínimamente el cráneo de la víctima, se emplearon métodos radiográficos para analizar los restos de la víctima que ayudarían en el juicio legal (Dirnhofer et al., 2006). Así, la mayoría de las contribuciones concernientes al uso de este tipo de técnicas para la realización de virtopsias se han desarrollado en Suiza. Algunos autores, como Michael J. Eva Scheured de la Universidad de Berna, Suiza, han sido pioneros en estos nuevos procedimientos. Estos investigadores diseñaron una técnica que permite trazar un mapa del interior del cadáver, que se ejecuta a través de escaneos de toda la superficie del cuerpo en tres dimensiones y mediante una exploración exhaustiva, por medio de resonancia magnética y tomografía axial computarizada (radiografías distintas en diferentes ángulos) (Joseph, Girish, Sathyan, Kiran y Vidya, 2017). Por lo anterior, la creación de la virtopsia se ha dimensionado como una técnica de nueva generación, mínimamente invasiva e independiente del experto forense que, habitualmente, emite conclusiones después de un examen post mórtem a través de una técnica convencional.

La virtopsia, al igual que la autopsia convencional, tiene un enfoque multidisciplinario que integra la medicina forense, la patología, la radiología, el procesamiento de imágenes, la física y la biomecánica (Bolliger et al., 2008). La virtopsia posee cuatro estrategias de análisis: a) escaneo de superficie tridimensional (3D)/ fotogrametría de diseño asistida por computadora; b) tomografía computarizada multicorte (TCMC); c) imagen por resonancia magnética (IRM), y d) espectroscopía de resonancia magnética (Bolliger et al., 2008). A continuación, se define cada una de las estrategias:

Escaneo de superficie tridimensional (3D)/ fotogrametría de diseño asistida por computadora. Es un método basado en realizar mediciones usando fotografías; se toman varias fotografías diferentes desde diversos ángulos y se analizan mediante el software TRITOP/ ATOS II (GOM, Braunschweing, Alemania) (Dirnhofer et al., 2006). Este software utiliza imágenes de alta velocidad y sensores remotos para construir una imagen integral en 3D de las características de la superficie del cadáver.

Tomografía computarizada multicorte (TCMC). Exhibe la arquitectura del tejido duro en múltiples secciones, y permite identificar cualquier cambio en él.

Imagen por resonancia magnética (IRM). Muestra las condiciones del tejido blando y conduce a la identificación de cambios en él. La TCMC y la IRM conjuntamente permiten la diferenciación de las estructuras adyacentes. 
Espectroscopía de resonancia magnética. Proporciona una imagen o información bioquímica del cuerpo. Emplea metabolitos en el cerebro que emergen de la descomposición post mórtem y que permiten estimar el momento preciso del deceso.

Técnicas complementarias. 1) Tomografía microcomputarizada: Los casos especiales requieren modificaciones de las técnicas mencionadas anteriormente. Así, el Instituto de Física Médica de Erlangen, Alemania, desarrolló un escáner para obtener imágenes de 3D con una resolución isotrópica que oscila entre 10 y 100 m; este escáner es sensible para examinar muestras de diámetros que varían de 4 a 40 mm (Joseph et al., 2017). 2) Microscopía de resonancia magnética: Permite obtener imágenes anatómicas in vivo de los globos oculares, los cuales son embebidos en parafina, se cortan en secciones de $6 \mu \mathrm{m}$, y se realizan tinciones con hematoxilina y eosina.

En la Figura 1 se muestra una representación esquemática del proceso de la virtopsia que, con el avance de la robótica, propenderá por el diseño de virtobots, máquinas que permitirán combinar la adquisición de datos provenientes de las cuatro estrategias de análisis empleadas en la virtopsia.

La Tomografía Computarizada Multidetector (TCMD), y su nueva modalidad la DSCT (de las siglas en inglés, Dual Dource Computed Tomography), es la herramienta usada con mayor frecuencia en todo el mundo en el estudio de las lesiones y de las causas de muerte de un individuo (Motta, Alva, y Herrera, 2013; Joseph et al., 2017). Por lo tanto, la identificación de hematomas ocultos, el estudio del impacto de armas de fuego y blancas y la respectiva trayectoria de la lesión, pueden ser de suma utilidad en el esclarecimiento de un caso. Además, las mediciones morfométricas de las lesiones son exactas y permiten una exhaustiva documentación del caso, que se puede someter a exámenes tantas veces como sea posible (EstudioGalton, 2010).

Ahora bien, para realizar una virtopsia se deben tener en cuenta los siguientes pasos: 1) Inicialmente, se prepara el cuerpo para el estudio, el cual será analizado por medio de adquisiciones digitales como la tomografía computarizada, resonancia magnética, escáneres de superficie, fotografía, entre otros elementos digitales, de manera conjunta, mediante un equipo que las integra, o de manera individual. Se procede a: 2) Identificar las estructuras anatómicas, separando las imágenes digitales y áreas de interés en ficheros DICOM, etiquetándolas para identificar el tejido o el área del cuerpo que se va a analizar, como sistema nervioso central, sistema respiratorio, cardiovascular, cavidad abdominopélvica; piel, tejidos subcutáneos, músculos, politraumatismos y heridas por proyectil de arma de fuego. 3) Si se desea realizar morfometría o registro, se procede a asignar puntos a cada uno de ellos, con el fin de ubicar exactamente las estructuras anatómicas, esto es, mediante fotogrametría, que es una técnica que se utiliza para determinar las propiedades geométricas de los objetos y su situación espacial a partir de imágenes, haciendo corresponder los puntos en la tomografía computarizada o la resonancia magnética y los que se obtienen del escáner de superficie (Motta et al., 2013). 4) Después de obtener las imágenes, el escáner permite hacer exploración de superficie y reconstrucciones multiplanares en $3 \mathrm{D}$, con cambios colorimétricos y/o bioquímicos de las estructuras, a decisión de quien analiza el estudio (Motta et al., 2013).

El procesamiento posterior de las imágenes puede proporcionar una visualización útil para presentar como prueba en un juicio. También se cuenta con un brazo robótico incorporado que permite al operador guiarse por las imágenes adquiridas del cadáver y obtener muestras post mórtem de órganos y tejidos. Las muestras de tejido se pueden utilizar para citología, histología química y análisis microbiológicos posteriores (Motta et al., 2013).

Las muestras para examinar pueden tener tamaños con diámetros entre 4 - $40 \mathrm{~mm}$. Se emplea un software que permite procesar y modificar las imágenes obtenidas, es decir, las imágenes pueden ser giradas, realzadas, amplificadas, medidas y convertidas en un modelo tridimensional, el cual, a su vez, también puede ser manipulado mediante ampliaciones y rotaciones posteriores para ser observado desde diferentes ángulos o perspectivas (Motta et al., 2013). 
Es útil el empleo de herramientas radiológicas en casos traumáticos, como fracturas óseas, lesiones no accidentales en niños y lesiones por arma de fuego. También es importante en muertes por ahorcamiento, estrangulamiento y ahogamiento, tanto en un cuerpo putrefacto como carbonizado. Por su parte, la resonancia magnética y tomografía computarizada (MR-CT) es el método de elección para investigar casos de muerte traumática, cuerpos descompuestos y carbonizados; es útil para determinar si una lesión ha sido causada o es accidental. Los datos obtenidos mediante esta metodología incluyen, por ejemplo, ubicación, tipo y configuración de una fractura, y a través de ellos se puede determinar el punto de impacto y su dirección, así como la forma del objeto con el que se causó la lesión (Lo Re et al., 2019).

De otro lado, en diferentes tipos de desastres masivos por causas naturales, accidentes o como resultado de acciones terroristas, se requiere el procesamiento y la identificación de un número elevado de víctimas; de esta manera, la disponibilidad de MR-CT, sala de informes y sistemas de enfriamiento, en esas circunstancias, se considera un gold estándar en víctimas masivas (Lo Re et al., 2019).

\section{Ventajas y desventajas de la autopsia virtual}

La virtopsia permite analizar en tiempo real las regiones anatómicas sin necesidad de abrir o mutilar el cuerpo; además, se puede realizar de una manera interactiva y sin alterar el modelo o el área específica en estudio. Esta técnica puede ser utilizada tanto en un cadáver como en una persona viva, y permite detectar detalles ocultos, las propiedades de los tejidos y las modalidades de lesión en modelos tridimensionales (EstudioGalton, 2010). Lo anterior se analiza mediante la creación y estandarización de ficheros gráficos obtenidos por resonancia magnética nuclear, tomografía computarizada, tomografía computarizada multidetector y radiografías, con el fin de tener mejores accesibilidad, almacenamiento, exploración y visualización de las imágenes tomadas (Montes, Otálora y Archila, 2013). Por lo anterior, la virtopsia es un proceso simple que no necesita preparación especial, solo requiere ubicar el cuerpo en una mesa especial y tomar imágenes digitales con los diferentes equipos tecnológicos, y de este modo el médico forense no tiene contacto directo con fluidos, gases tóxicos, posibles contaminaciones por virus y/o bacterias que sean perjudiciales para su salud o, simplemente, por solicitud de los familiares de las víctimas por situaciones religiosas, por ejemplo (Badam et al., 2017). En caso que se requiera una segunda opinión pericial, las imágenes estarán siempre disponibles en archivos específicos, siendo éste uno de los principales beneficios de la autopsia virtual (Nogué, Bardalet y Adserias, 2016).

La virtopsia tiene algunas limitantes, en primer lugar, este sistema disminuye la visualización de algunas lesiones y no permite ver el color de los órganos cuando los equipos de análisis poseen una baja resolución. Además, requiere la experticia y la capacidad de observación de las lesiones del cadáver por parte de un médico forense, el cual se encarga de determinar en el cuerpo detalles asociados a su estado tafonómico, tanto ante mórtem como post mórtem (Nogué et al., 2016). Los elevados costos de los equipos tecnológicos y la falta de medios son una desventaja para países latinoamericanos como Colombia; sin embargo, esta técnica, podría aplicarse como un método complementario, y no necesariamente como un método que pueda sustituir a la autopsia convencional.

Las aplicaciones de la virtopsia son importantes en algunas áreas forenses como patología y antropología forense, tanatología, accidentología vial, entre otras, al determinar el tiempo de muerte, la identificación de individuos y la exposición a agentes tóxicos, así, se convierte en una alternativa o prueba pericial adicional en algunos casos forenses (Badam et al., 2017).

En los últimos años, se han empleado principalmente dos tipos de técnicas para la reconstrucción de imágenes tomadas de cadáveres: 1) Reconstrucción 3D que permite la producción de resultados más específicos y esperados dentro de un análisis de una imagen digitalizada, es capaz de reconstruir cualquier tipo de lesión y, por ende, del suceso ocurrido asociado al caso. 2) Además de generarse un modelo tridimensional, éste puede ser sometido a visualizaciones interactivas, es decir, 
se pueden procesar virtualmente estas imágenes y someterlas para la determinación de cálculos de volúmenes, trayectorias, ángulos o cualquier otro objeto con evidencia de interés. También se utiliza en las reconstrucciones animadas de los diferentes sucesos a partir de los elementos materiales probatorios y evidencias físicas de índole científica que puedan obtenerse del hecho. De esta manera, podría facilitarse la obtención de resultados y conclusiones que favorezcan la aceptación o rechazo de las posibles hipótesis planteadas en el caso (EstudioGalton, 2010).

Por lo anterior, con la virtopsia se pueden reconstruir regiones corporales, realizar una visualización de los ficheros para examinar datos obtenidos por las técnicas de radiología digital en tiempo real de las imágenes, siendo esto, una combinación de las técnicas de proceso y de análisis de imagen, que permite girar, realzar, medir, convertir una imagen en un modelo tridimensional para el desarrollo de una mejor inspección del cuerpo (Badam et al., 2017). Se realiza un examen exhaustivo sobre las imágenes digitalizadas, permitiendo obtener información acerca de algunas de las características del objeto $u$ objetos a que corresponden las imágenes (EstudioGalton, 2010). Así, se puede examinar las diferentes áreas estudiadas midiendo su tamaño, forma, perímetro, el número de objetos determinados, su densidad óptica; color, distancia entre objetos o formas, ángulos, trayectorias, etc. La ventaja es que se puede realizar interactivamente y sin alterar el modelo, y queda siempre disponible para continuar el análisis (Joseph et al., 2017).

\section{Viabilidad de incorporar de manera permanente o continua este tipo de tecnología a Colombia}

Los beneficios de la autopsia virtual son numerosos y reconocidos por la comunidad científica (Motta et al., 2013). Se puede afirmar que la virtopsia es un procedimiento que permite llevar a cabo un estudio completo de los cuerpos, ya que puede procesar y facilitar ficheros de imágenes computarizadas producto de radiología digital, tomografía computarizada y resonancia magnética, lo que permite garantizar la buena calidad de un trabajo médico forense para la comparecencia en un proceso penal. Esta técnica se refiere a la utilidad y necesidad de emplear mayor tecnología para un análisis más rápido, acertado y eficaz del cuerpo, que posteriormente ayudará al médico forense a interpretar la causa de muerte de la víctima de manera más óptima (Nogué et al., 2016).

La virtopsia inició en Suiza en el año 2000 con el uso de la tomografía computarizada y la resonancia magnética para obtener una visualización detallada de un cadáver; países como Alemania, Australia y Estados unidos también han implementado estas técnicas (EstudioGalton, 2010). Por su parte, la experiencia de las autopsias virtuales en el Centenario Hospital Miguel Hidalgo de la Universidad Autónoma de Aguascalientes en México, ha permitido desarrollar la técnica con la implementación de nuevos métodos y equipos para realizar autopsias como ecografías post mórtem y endoscopias cadavéricas (Nogué et al., 2016). Otros países de América también hacen uso de estas técnicas como Argentina, Cuba y Ecuador; en este último, específicamente, la Universidad Técnica Particular de Loja (UTPL) es la primera institución donde se detallan técnicas similares a la virtopsia, ya que reúne otras herramientas como la realidad aumentada y laboratorios virtuales (Carrera, 2017).

En el marco del tercer Congreso Internacional de Medicina Legal y Ciencias Forenses, se presentaron avances para la realización de virtopsias; a este evento asistió el Dr. Carlos Eduardo Valdés, director general del Instituto de Medicina Legal y Ciencias Forenses de Colombia, que conoce el uso de la virtopsia y las ventajas que trae consigo (Sociedad Argentina de Radiología, 2016). Aunque Colombia no implemente la virtopsia como técnica complementaria a la autopsia convencional, este país tiene la capacidad de realizar imágenes digitalizadas obtenidas por medio de la resonancia magnética, lo cual se lleva a cabo en la Universidad Nacional sede Bogotá, donde está ubicado el Laboratorio de Resonancia Magnética Nuclear (RMN). Este tipo de laboratorio dentro del territorio nacional podría tener un enorme potencial cuando se piense en un trabajo colaborativo con el Instituto Nacional de Medicina Legal y Ciencias Forenses de Colombia y con otras universidades encargadas de la formación de investigadores en el área de criminalística y ciencias forenses, como el Tecnológico de Antioquia 
- Institución Universitaria. Estas herramientas proveerán elementos académico-científicos para la mejora de la medicina, el derecho y las ciencias forenses a fin de lograr una máxima eficiencia en la salud y en la investigación judicial (Motta et al., 2013).

Otro método que también se utiliza en Colombia es la radiología, la cual tiene aplicaciones de importancia para esclarecer delitos y así apoyar la administración de justicia. Entre sus aplicaciones se encuentran: estudio de muertes por accidentes aéreos y desastres, documentación de lesiones en accidentes de tránsito, necropsias médico-legales en muertes por asfixias mecánicas, estudio de muertes asociadas a heridas por proyectiles de arma de fuego, diagnóstico del maltrato infantil, verificación de la autenticidad de la evidencia física, identificación de cadáveres, examen en muertes fetales, lesiones personales, determinación de edad y examen de restos óseos (Montes et al., 2013).

De acuerdo con lo anterior, se han presentado progresos en la región en cuanto a la implementación de nuevas tecnologías para la realización de virtopsias; conseguir estas metas significa contribuir a las investigaciones judiciales y hacerlas más eficaces. La autopsia virtual puede ser de importante utilidad como complemento de las autopsias convencionales y se espera que en el futuro se pueda implementar como su complemento habitual o incluso como su sustituto (Nogué et al., 2016).

\section{Discusión y conclusión}

La autopsia virtual comenzó como un proyecto de investigación multidisciplinario y tecnológico en las áreas de las ciencias forenses y la salud. La resonancia magnética de cuerpo entero, la tomografía computarizada y la espectroscopia han sido útiles para el análisis de personas vivas; sin embargo, se han convertido en herramientas que la medicina forense comienza a implementar para estudiar digitalmente los cadáveres. La virtopsia traza un mapa interno de la víctima para visualizar los trastornos que la llevaron a la muerte. Una de sus ventajas es que se respeta la integridad del cuerpo, algo sumamente importante para los familiares y para algunas religiones, al tiempo que se conserva el organismo en mejores condiciones, lo que permite realizar posteriores análisis las veces que una investigación lo requiera (Sociedad Argentina de Radiología, 2016).

La tragedia del Boeing 737 de LAPA y el atentado de la AMIA, fueron casos catastróficos en los que los forenses tuvieron dificultades para identificar los cadáveres y restos humanos. En estos casos, la radiología y la tomografía pueden ser herramientas esenciales para la identificación de las víctimas; el cotejo radiológico post mórtem comparado con datos ante mórtem que aportan familiares, resulta fundamental para la identificación de cadáveres. En otros casos, la autopsia virtual tiene especial relevancia en aquellas autopsias de "alto riesgo", como las que se realizan a personas fallecidas por virus hemorrágicos como el ébola o en casos de atentados con gases tóxicos, en donde la intervención del cuerpo puede poner en peligro la vida de los forenses y del equipo de profesionales que interviene en la autopsia (Sociedad Argentina de Radiología, 2016). No obstante, los expertos consideran que esa tecnología no va a reemplazar la autopsia convencional, sino que será una herramienta complementaria. Por ejemplo, el diagnóstico por imágenes no reemplaza la evaluación realizada por el médico patólogo; la autopsia virtual no identifica la estricnina, el cianuro o el alcohol, los cuales sí son detectados por análisis químicos o toxicológicos convencionales. Las técnicas son siempre complementarias y permiten perfeccionar los diagnósticos, pero no podrán sustituir fácilmente al ser humano en la interpretación de los hechos y en la confección del diagnóstico definitivo (Sociedad Argentina de Radiología, 2016).

La virtopsia pretende mejorar la eficiencia en la investigación en casos legales y servir de apoyo a la autopsia convencional. Estas nuevas tecnologías facilitan la extensión del sistema legal, y se espera que se puedan implementar como complemento habitual en Colombia.

Conflicto de intereses: Los autores declaran no tener conflictos de intereses. 


\section{Referencias bibliográficas}

Badam, R. K., Sownetha, T., Babu, D. B., Waghray, S., Reddy, L., Garlapati, K., \& Chavva, S. (2017). Virtopsy: Touch-free autopsy. Journal of Forensic Dental Sciences, 9, 42-46.

Bolliger, S. A., Thali, M. J., Ross, S., Buck, U., Naether, S., \& Vock, P. (Feb. 2008). Virtual autopsy using imaging: bridging radiologic and forensic sciences. A review of the Virtopsy and similar projects. Eur Radiol. 18(2), 273-282.

Breitbeck, R., Ebert, L., Ptacek, W., Kronreif, G., Furst, M., \& Thali, M. (19-20 November 2013). Virtobot - A Robot System for Optical 3D Scanning in Forensic Medicine. Proc. of the 4th International Conference on 3D Body Scanning Technologies (pp. 84-91). Long Beach CA, USA.

Carrera, V. (2017). Virtopsia. Un mundo virtual para aprender medicina legal. [Artículo en un Blog]. Universidad Técnica Particular de Loja (UTPL), Ecuador. Recuperado de https://noticias.utpl.edu. ec/virtopsia-un-mundo-virtual-para-aprendermedicina-legal

Castro, C., Roque, L., Garcés, B. R., y Oliver, M. (2017). Consideraciones sobre autopsia desde una perspectiva ciencia, tecnología y sociedad. Medisur, 15(5), 666-675.

Dirnhofer, R., Thali, M. J., Jackowski, C., Potter, K., y Vock, P. (2007). Virtopsy: Minimally invasive, imaging-guided virtual autopsy. RadioGraphics, 26(5), 1305-1333.

EstudioGalton (2010). Virtopsia (Autopsia Virtual). Galton - Estudio pericial accidentológico y documentológico. [Internet]. Recuperado de https://estudiogalton.wordpress.com/author/ estudiogalton/page/7/

Gisbert Calabuig, J. A. (2004). Autopsia: definición. Autopsia clínica y autopsia médicolegal. Legislación. Técnicas de autopsia del raquis. En G. Calabuig, Medicina Legal y Toxicología (pp. 1-9) (6. ed.). España: Elsevier.

Instituto Nacional de Medicina Legal y Ciencias Forenses. (2004). Guía de Procedimientos para la
Realización de Necropsias Médico legales. (2. ${ }^{a}$ ed.). Bogotá: INMLYCF.

Joseph, T. I., Girish, K. L., Sathyan, P., Kiran, M. S., \& Vidya, S. (2017 Sep-Dec.). Virtopsy: An integration of forensic science and imageology. J Forensic Dent Sci., 9(3), 111-114.

Lo Re, G., Salerno, S., Terranova, M. C., Argo, A., Lo Casto, A., Zerbo, S., \& Lagalla, R., (2019). Virtopsy and Living Individuals Evaluation Using Computed Tomography in Forensic Diagnostic Imaging. Seminars in Ultrasound, CT and MRI, 40(1), 67-78

Ministerio de Salud Pública de Colombia. (17 de abril de 1990). Decreto 786 de 1990. "Por el cual se reglamenta parcialmente el Título IX de la Ley 09 de 1979, en cuanto a la práctica de autopsias clínicas y médico - legales, así como viscerotomías y se dictan otras disposiciones. Diario Oficial, 39.300 .

Montes, G. A., Otálora, A. F., \& Archila, G. A. (2013). Applications of conventional radiology in the medical forensic field. Review of Colombian Radiology, 24(4), 3805-3817.

Motta, G. A., Alva, M., y Herrera, R. A., (2013). La autopsia virtual (virtopsia): La radiología en la Medicina Forense. Rev Sanid Milit Mex, 67(3), 115123.

Nogué-Navarro, L., Bardalet, N., y Adserias, M. J. (2016). Técnicas de apertura del cadáver. Medicina Legal de Costa Rica, 33(1), 3-14.

Pomara, C., Fineschi, V., Scalzo, G., \& Guglielmi, G. (2009). Virtopsy versus digital autopsy: Virtual autopsy. Radiol Med., 114(8), 1367-1382.

Sociedad Argentina de Radiología. (26 de septiembre de 2016). ¿Qué es una autopsia virtual? Una nueva herramienta para la medicina forense. Intramed. [Internet]. Recuperado de https://www.intramed. net/contenidover .asp? contenidoid $=42738$

Teijeira, R., Bañón, R., Hidalgo, A., y Pradini, I., (2006). La autopsia médico-legal. Medicina Clínica, 126(20), 787-792. https://doi.org/10.1157/13089117 


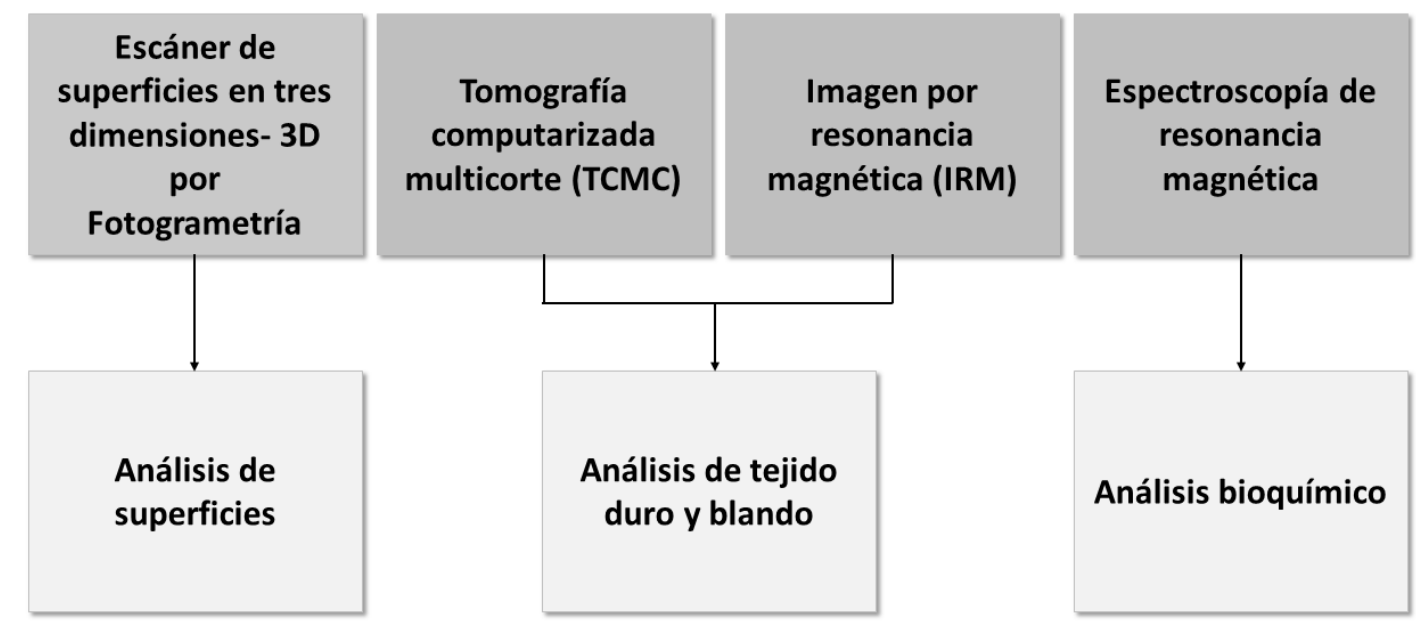

Figura 1. Representación esquemática del proceso de la virtopsia 


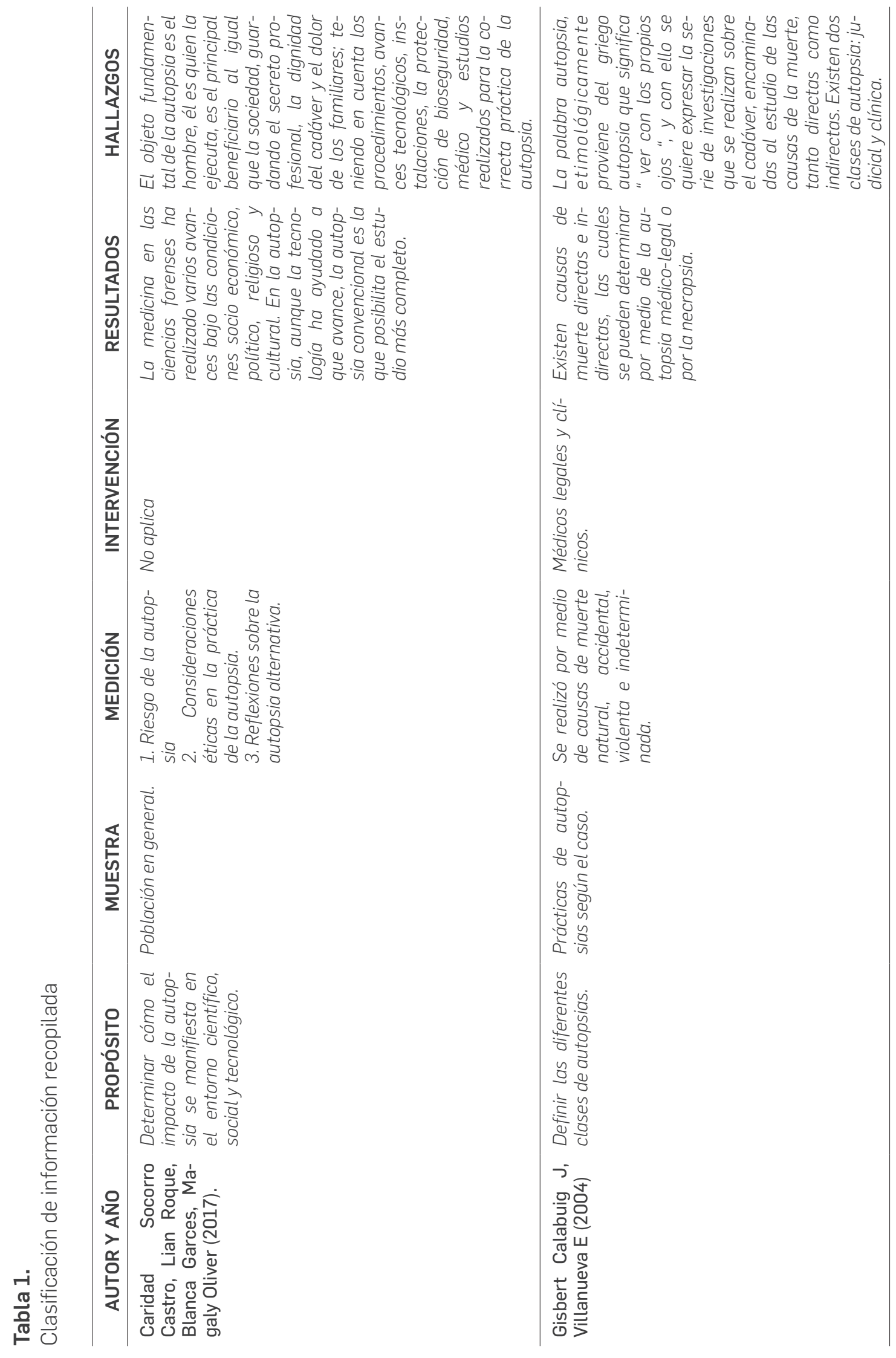




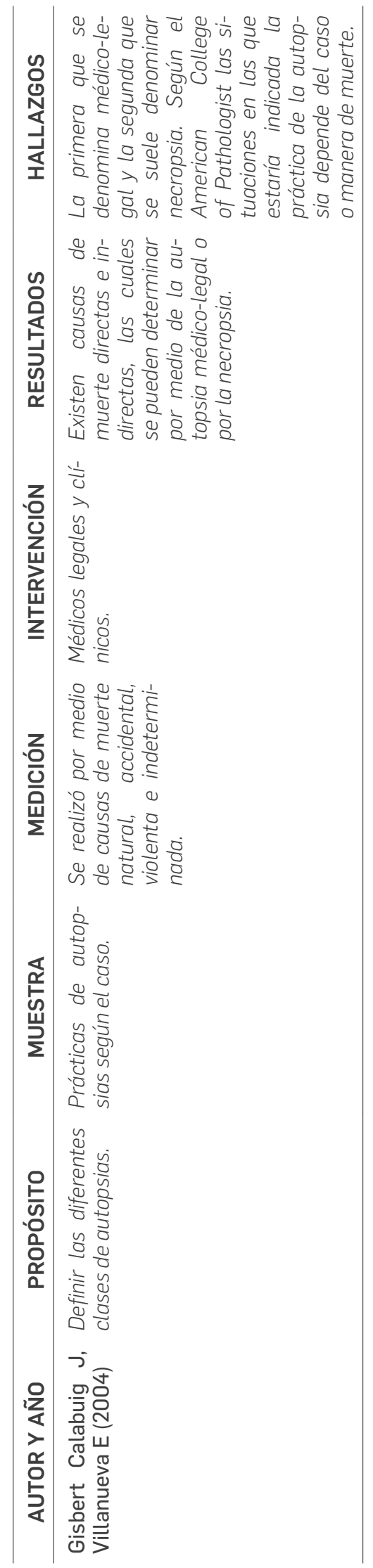

\&

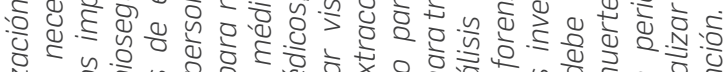

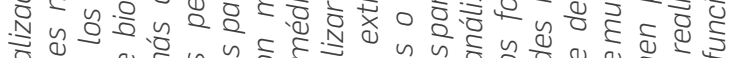

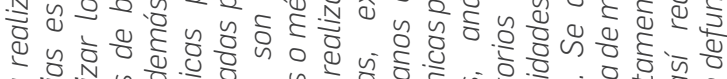

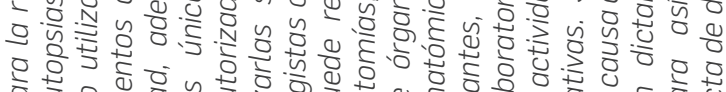

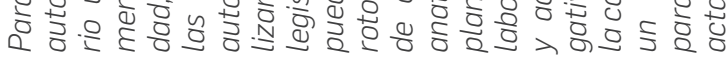

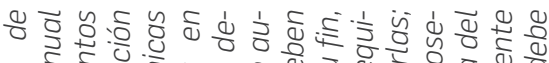
œ

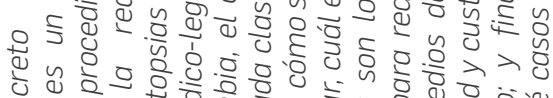

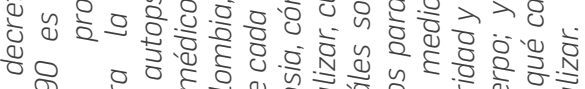

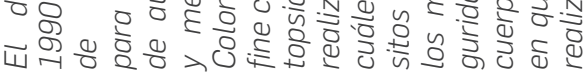

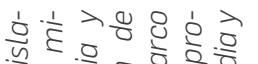

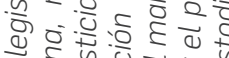

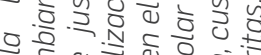

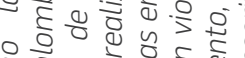

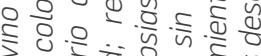

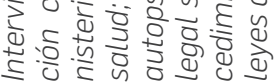

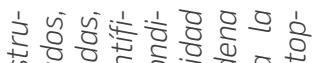

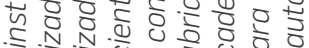

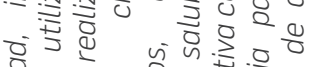

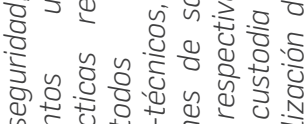
की है है है

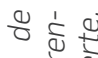

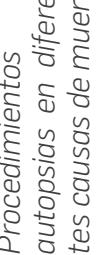

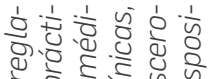

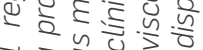
व $0 . \frac{0}{4}>0$ \%

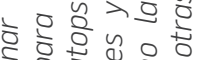

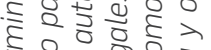

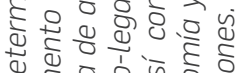

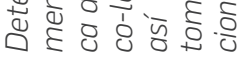

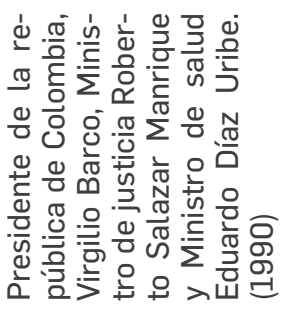




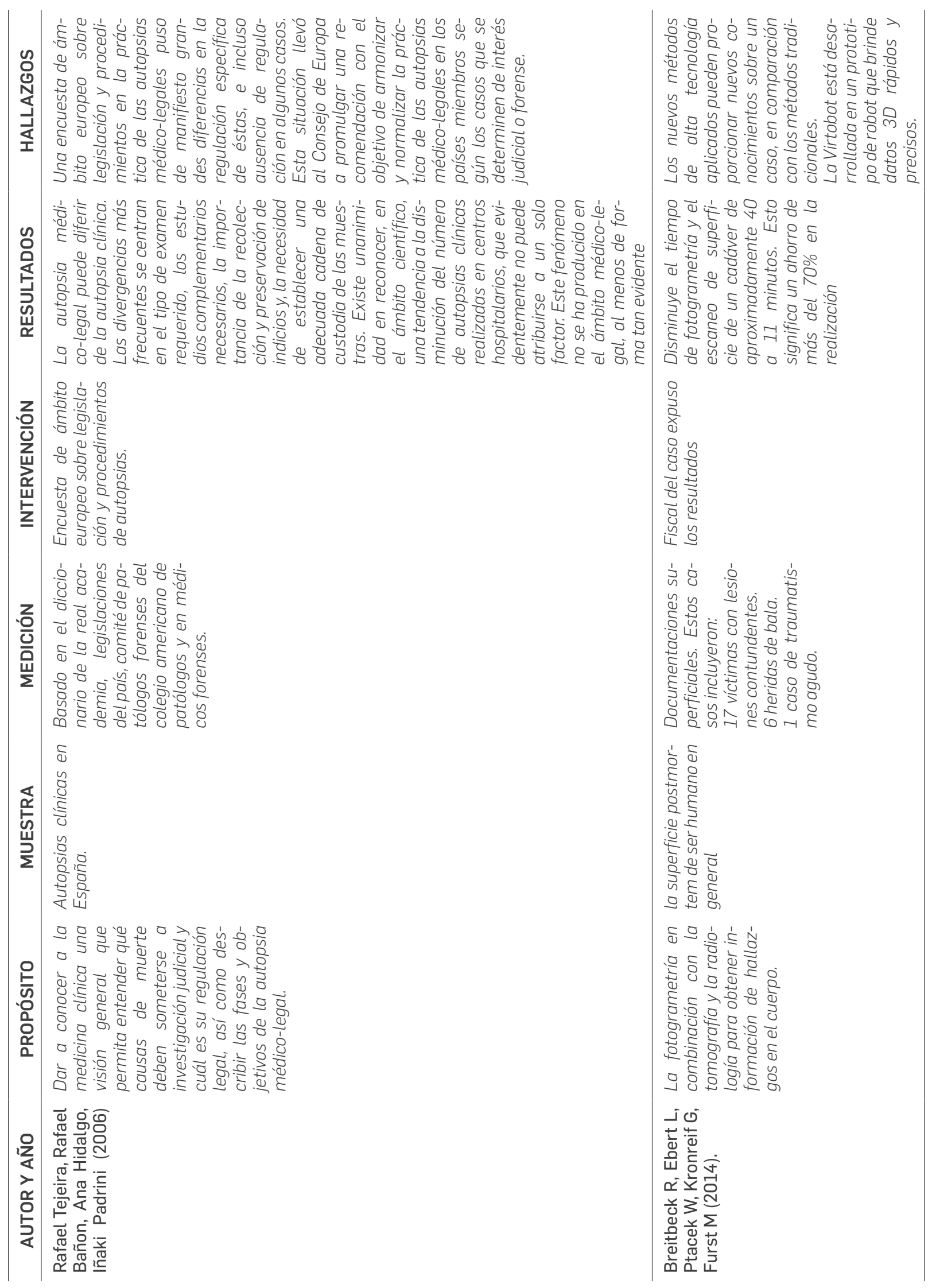




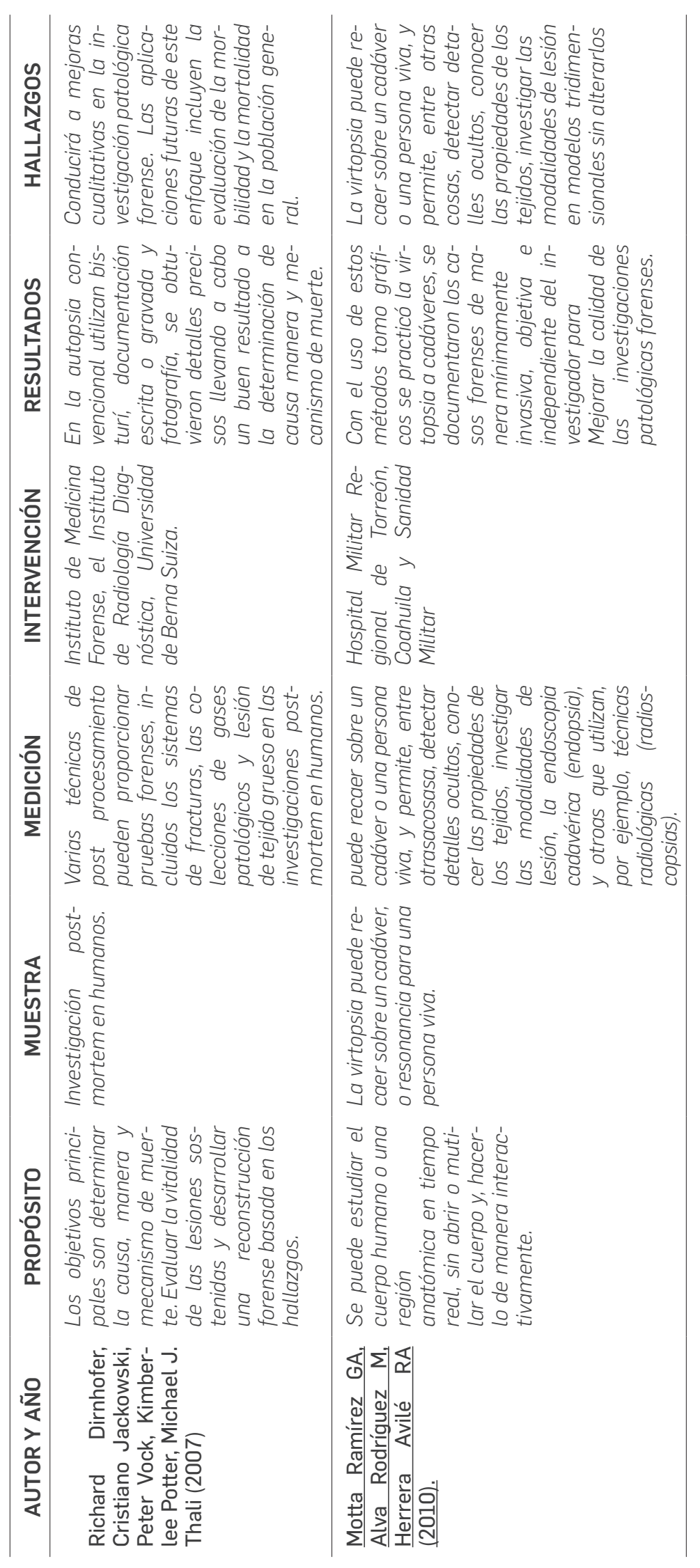

